Banco Interamericano de Desarrollo (2014).

WEB

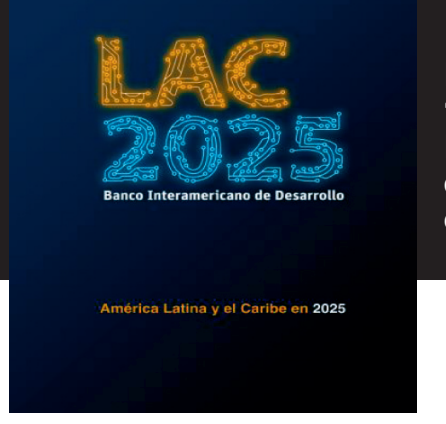

"América Latina y el Caribe en 2025

Documento Electrónico (resumen ejecutivo en español) recuperado de: http://publications.iadb. org/handle/11319/6428?locale-attribute=es

\title{
América Latina y el Caribe en 2025
}

América Latina y el Caribe en el 2025, por sus siglas en inglés LAC 2025. Es una iniciativa del Banco Interamericano de Desarrollo que plantea tendencias y proyecciones futuras que impactarán la calidad de vida de los latinoamericanos y caribeños en el 2025. Este documento constituye una predicción de las áreas más significativas de la región, teniendo a la base datos del pasado y presente, con los cuales puede plantearse un futuro probable. De acuerdo a estas características, se considera un estudio del futuro del tipo emancipador.

El documento LAC 2025, aborda 12 áreas de importancia: macroeconomía y competitividad; soja, software, energía, demografía y género, urbanismo, seguridad ciudadana, transporte y movilidad, espacios verdes, salud, educación y gobernabilidad.

Respecto a la macroeconomía y competitividad, para el 2025, América Latina tendría un crecimiento promedio anual del 3.7\%; la clase media alcanzaría unas 460 millones de personas y la región representaría el 7\% del PIB mundial.

En cuanto a la soja, Brasil y Argentina, dos de los cuatro países productores de soja en el mundo, se estarían anticipando a los efectos del cambio climático debido a su inversión en biotecnología e investigación genética, logrando con ello producciones hasta de un $30 \%$ por hectárea.

En relación a las tecnologías de información y software, los polos más importantes de desarrollo serán Buenos Aires, Montevideo, San José, Ciudad de México, Guadalajara, Bogotá, Campinas, Sao Pablo, Córdoba y Santiago.

Respecto a la energía, el consumo de ésta podría incrementar por lo menos en un $40 \%$, por lo cual el gas natural podría constituir una opción ya que es abundante y menos contaminante en la región; pero se necesitaría de una inversión mínima de 200 mil millones de dólares americanos para complementar los abastecimientos de energía renovable (eólica, solar e hidroeléctrica) las cuales solo cubrirían un tercio de las demandas para el 2025.

En cuanto a la demografía y género, se incrementará la población, pero el número de hijos disminuirá a dos y la expectativa de vida para hombres y mujeres será de 77 años como promedio. La fuerza laboral de las mujeres aumentará en un $42 \%$, por tanto, la brecha salarial entre géneros se habrá reducido en un $8 \%$ y las mujeres tendrán más oportunidades en el parlamento. 


\section{WEB}

Respecto al urbanismo, se espera que la población viva en las ciudades, por lo que se incrementará en más de 10 millones de habitantes en Bogotá, Lima, México DF, Sao Paulo, Rio de Janeiro y Buenos Aires. Este fenómeno obligará a interconectar ciudades en distancias mayores de 60 kilómetros. Para ello se implementarán 3 mega corredores urbanos en las ciudades más pobladas de la región: Rio de JaneiroSao Paulo-Campinas; Toluca-México-Puebla y Buenos Aires-Rosario-Córdova. Y aunque el BID ha identificado 140 ciudades emergentes que podrían duplicar sus poblaciones, se caracterizaran por estar hiperconectadas. Este fenómeno facilitará la exposición de información privada y pública lo que revolucionará el manejo de los problemas que actualmente preocupan.

En relación a la seguridad ciudadana, América Latina hará frente al flagelo de la violencia mediante el manejo estratégico de la información la cual estará en cantidad y disponibilidad. Para ello usará el sistema de mapeo georeferencial, el cual divide a una ciudad en cuadrantes y permite saber en detalle dónde ocurre el crimen, día, hora, quienes lo cometen y bajo que circunstancias.

En cuanto al transporte y movibilidad, se prevé que el número de automóviles incrementará en 140 millones, los cuales serán nuevos, tendrán GPS y estarán conectados a la internet. También como alternativa para la región se incrementará Ios Buses de Tránsito Rápido o BRTs, los cuales reducen el tiempo de desplazamiento y congestión; y sobre todo mejoran la calidad de aire. Además se planean unos 20 proyectos de sistemas subterráneos y el incremento del uso de la bicicleta como alternativa de transporte.

Al respecto de los espacios verdes, muchas ciudades harán grandes inversiones para recuperar ríos y bahías bajo la presión ciudadana.

En relación a la salud, se estiman incrementos en los niveles de sobrepeso y obesidad, debido al consumo elevado de comida "chatarra" y ausencia de actividad física. Lo cual ocasionará más prevalencia de enfermedades crónicas como la diabetes; pero dada la hiperconectividad, los gobiernos aprovecharan el uso de tecnologías para cambiar hábitos de consumo y estilos de vida.

Respecto a la educación, se revolucionará aún más las formas de enseñar, a través del uso de la tecnología lo cual obligará a modificar los roles tradicionales del profesor y estudiante; ampliando los escenarios de aprendizaje del mundo virtual.

Finalmente, los latinoamericanos y caribeños serán más exigentes en cuanto al ejercicio de la democracia, ya que tendrán más acceso a información y harán uso de las redes sociales para expresar sus demandas. Los líderes urbanos aprovecharan la conectividad para crear nuevos espacios de participación ciudadana.

Sinopsis a cargo de Licda. Brenda Gallegos Profesora de la Facultad de Medicina Universidad de El Salvador 